\title{
Julio Cabilla Alberto, practicante y periodista de Cádiz (1897-1955)
}

\author{
Mariana García González \\ Enfermera responsable del Hospital SS San Carlos, San Fernando (Cádiz). \\ Antropóloga. Miembro del Grupo de Investigación de Historia de la Enfermería \\ gaditana del Colegio de Enfermería de Cádiz \\ Manuel Cano Leal \\ Teniente Coronel enfermero (Reserva), Secretario del Colegio de Enfermería de \\ Cádiz. Miembro del Grupo de Investigación de Historia de la Enfermería gaditana del \\ Colegio de Enfermería de Cádiz.
}

RESUMEN: La historiografía de la Enfermería Gaditana nos remite a los orígenes de su organización colegial, principios del siglo XX. Los datos obtenidos para la reconstrucción histórica profesional proceden principalmente de la revista que el Colegio de Practicantes editó desde 1916 a 1939, publicación que vio la luz gracias a profesionales de merecido reconocimiento como Julio Cabilla Alberto, quien a pesar de su juventud asumió la dirección de El Practicante Gaditano y su puesta en marcha. Su biografía se fundamenta en fuentes primarias documentales, como es el expediente personal (Archivo Diocesano Cádiz) y el académico depositado en el Archivo de la Universidad de Cádiz.

Palabras clave: Cádiz, Colegio de Practicantes, Enfermería.

\section{Julio Cabilla Alberto, assistants in medicine and surgery and journalist from Cadiz (1897-1955)}

ABSTRACT: The historiography of the nursing Cádiz refers us back to the origins of your organization associative, beginning 20th century. The data obtained for the historicall reconstruction profesional come mainly from the magazine published by the

DOI del artículo:

http://dx.doi.org/10.25267/Cuad investig fondos arch UCA.2

Editorial ad UCA $\underline{019 . i 1.02}$ 
Association of Medical Assistants in medicine and surgery from 1916 to 1939, publication that saw the light tranks to professionals of deserved recognition as Julio Alberto Cabilla, who, despite his youth, took the address of El Practicante Gaditano and its commissioning. His biography is based om documentary primary sources as it is the personal record (File Diocesan Cádiz) and academic deposited in the University of Cádiz Archive.

Keywords: Cádiz, Association Medical Assistants in medicine and surgery, Nursing.

\section{INTRODUCCIÓN}

La historia social y profesional de finales del siglo XIX y del primer tercio del siglo XX en Cádiz, está inmersa en un ambiente convulso que afecta a todas las capas sociales. Es un hecho que podemos contemplar a nivel nacional en general, pero que en la capital gaditana está localmente influenciada además por el contexto político de la pérdida de las últimas colonias de ultramar en 1898, que arruina los sectores más importantes del tejido social, económico y laboral gaditano.

Julio Cabilla y Alberto, nace en el seno de una familia humilde en Cádiz, a las nueve de la noche de un 16 de junio de 1897. Su padre, Sebastián Cabilla Rondán, operario de los Astilleros gaditanos, su madre María del Carmen Alberto González, dedicada al servicio doméstico en casa de gente adinerada. Ambos naturales de la cercana ciudad de San Fernando, donde se habían casado el 3 de marzo de 1892 (Archivo Histórico Diocesano).

Se le puso por nombre Manuel Julio Lutgardo del Sagrado Corazón de Jesús. Julio, desde muy pequeño aprendió a superar todo tipo de adversidades y terminar una carrera que, aunque humilde, le valdría para afrontar la vida de una forma digna.

Imagen 1. Fotografía de Julio Cabilla Alberto.

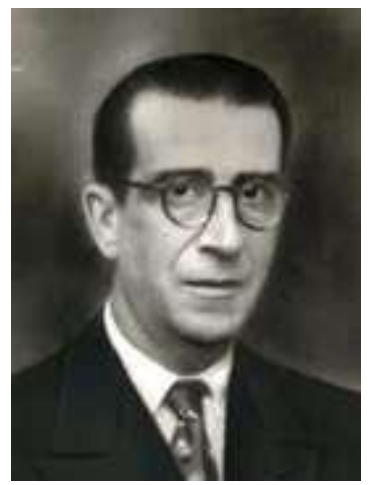

Fuente: Langa Nuño, Concha (2009)

DOI del artículo:

http://dx.doi.org/10.25267/Cuad investig fondos arch UCA.2 
Imagen 2. Certificado de la partida de bautismo

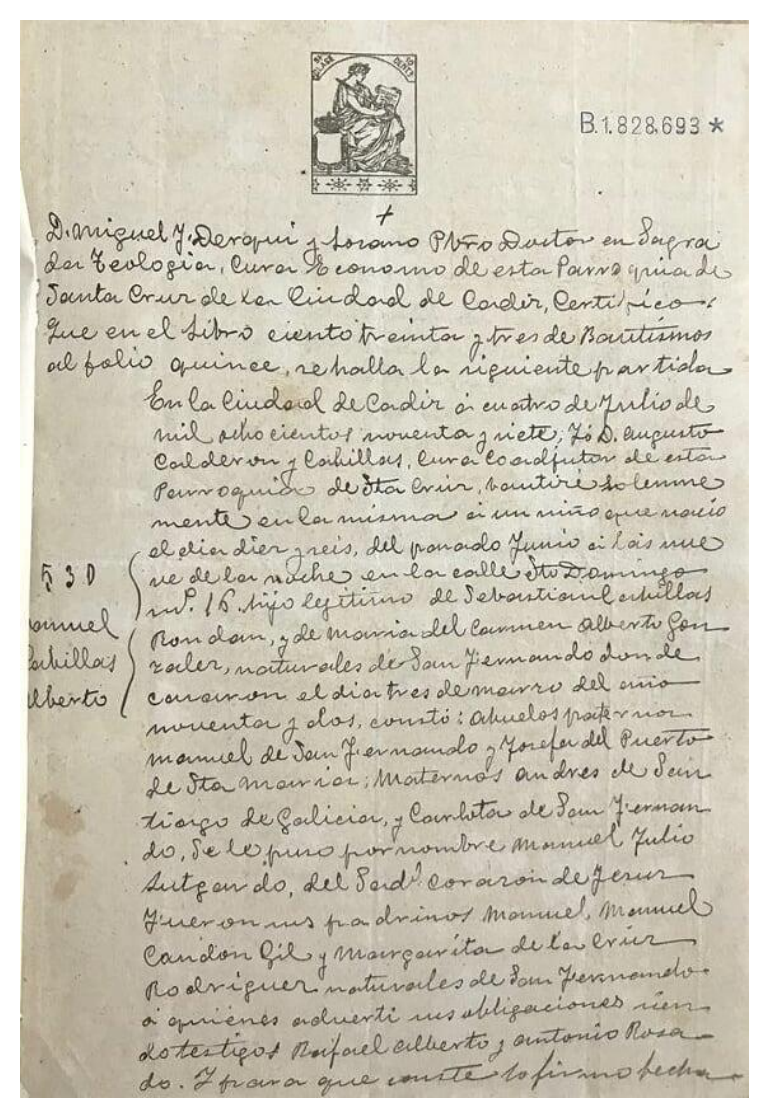

Fuentes: Archivo Histórico Diocesano. Obispado de Cádiz

\section{ASPECTOS ACADÉMICOS Y PROFESIONALES}

Como relata su hija María de los Santos (Langa, 2009), su padre era un autodidacta y eso también le sirvió para que, desde muy joven, se relacionara y a la vez aprendiera de compañeros que ya habían tenido una gran trayectoria personal y profesional, aportando sus propias iniciativas.

Sin cumplir la edad reglamentaria, el 15 de mayo de 1913, se matricula en la Facultad de Medicina de la capital gaditana, para poder examinarse del primer Curso de la carrera de Practicantes. El 30 de junio de 1913, obtiene en los exámenes ordinarios, la calificación de APROBADO.

Recién cumplidos los 16 años, se matricula el 30 de agosto de 1913, para poder examinarse de forma extraordinaria, del segundo Curso de la carrera de Practicantes, obteniendo la calificación de APROBADO, según Acta de examen de fecha 27 de septiembre de 1913 (Archivo de la Universidad de Cádiz). 
Imagen 3. Solicitud para el examen de reválida de Practicante.

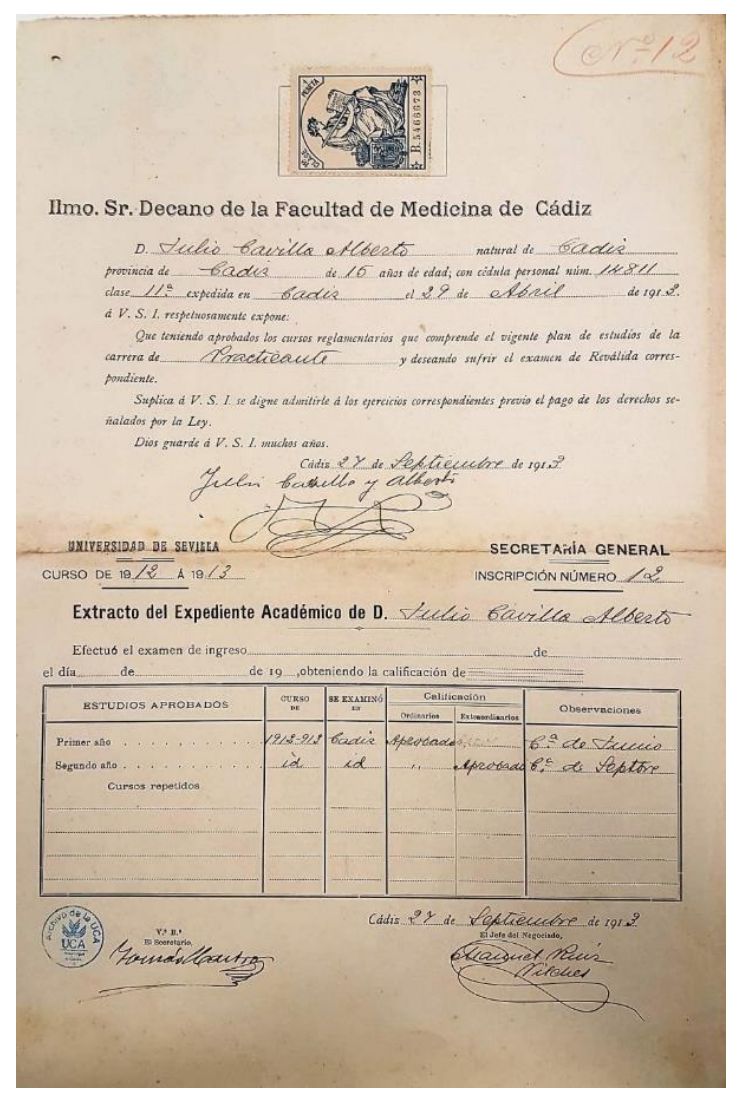

Fuente: Archivo de la Universidad de Cádiz (AUCA). Expediente personal de Julio Cabilla, C165 (3)-74 FM

\section{EL PRACTICANTE GADITANO}

Tres años después, junto al presidente del Colegio Provincial de Practicantes de Cádiz, Fernando Ceballos Cerezo, otro ilustre personaje de la Historia de la Enfermería Gaditana, fundan la primera revista profesional del Colegio, comenzando de alguna forma su trayectoria como periodista.

Desconocemos la relación de amistad con Ceballos, pero es evidente que de alguna forma, Cabilla impresionó por sus capacidades particulares, en cuanto a oratoria, ideas y proyectos de futuro, para encomendarle tan difícil tarea a un joven de escasos 19 años. La puesta en marcha de la publicación era un sueño hecho realidad, para un colectivo que intentaba consolidar su identidad profesional y corporativa, en medio de un complicado entramado laboral.

La constitución de la revista queda recogida en el Acta de la Junta General Ordinaria, del 22 de octubre de 1916. En la misma, entre otros puntos de interés, se 
acordó por unanimidad subvencionar con diez pesetas mensuales la publicación, con el título de "El Practicante Gaditano", periódico que ha de ser defensor de los intereses de la Clase y en el que podrán colaborar todos los practicantes colegiados. Se levantó la sesión a las cinco de la tarde, actuando de secretario Andrés Martínez Pérez (Diario de Cádiz, 23 octubre 1916).

Posteriormente, en Sesión General Extraordinaria (Diario de Cádiz, 10 noviembre 1916), se dio a conocer el proyecto acordado. Al mismo tiempo que se acordó designar como director al colegiado Don Julio Cabilla y Alberto y como administrador a Don Andrés Martínez Pérez.

En noviembre de 1916, sale a la luz el primer número de El Practicante Gaditano: Revista mensual, Profesional y Científica. Cabilla se estrena con un interesante artículo El Intrusismo Avanza, una práctica más que habitual, ejercida por pseudo profesionales (topiqueros, barberos, sangradores, etc.) que ocasionaban un grave perjuicio a la modesta clase de Practicantes. (Alberto, 1916)

Julio Cabilla, ocupó la dirección de la Revista desde los inicios hasta diciembre de 1917. En enero de 1920 vuelve a la dirección de la misma hasta diciembre de 1920, donde finaliza esta relevante experiencia periodística.

En esta segunda fase, se puede evidenciar un aumento exacerbado en sus compromisos profesionales y políticos. Para muestra el primer artículo de esta segunda dirección de la Revista, donde entre otras cosas dice:

La clase que por sus esfuerzos sigue avanzando hacia nuevos horizontes, se vincula con todas las clases sanitarias, defiende sus mismas teorías, se arraiga en su lucha y vencerá como venció siempre todo el que luchó por un ideal bien equilibrado.

Hoy, esa unión reciente con los humanos mayores de la profesión, forma un inmenso bloque de resistencia contra los desmanes de políticas caciquiles que hasta ahora han preterido estas importantes clases que siempre prestaron servicios encomiásticos, sin los resultados positivos a que en realidad fueron acreedores, por siempre y en todo momento me encontraréis al pie del cañón en defensa de los intereses sagrados de nuestra clase y dispuesto a unir mi voz con los compañeros que en la prensa piden justicia, ya que no remuneraciones para la clase que aprisionada empieza a ampliar sus pulmones con el aire de la prosperidad. (Alberto 1920)

La revista supuso un revulsivo para el colectivo de practicantes de la provincia, y para Cabilla un medio para difundir sus ideas y pretensiones profesionales y sociales. 


\section{VIDA FAMILIAR}

A mediados de marzo de 1921, en la Parroquia de San Lorenzo de Cádiz, Julio Cabilla y Alberto contrajo matrimonio con Carlota Linares Lamadrid, ambos con 23 años de edad, actuando como testigos Ricardo González Jurado, practicante, Francisco Bolaino Vázquez, embarcado, y Julio González de la Maza, industrial ${ }^{1}$.

De esta unión nacen siete hijos: María del Carmen, Concha, María de los Santos, María Teresa, Mercedes, Rosario y Julio.

Julio Cabilla compatibilizaba su actividad profesional trabajando en el negocio familiar de su esposa, "La droguería americana", un comercio con bastante prestigio y en donde además residía su casa, en la calle Hospital de Mujeres. En aquella época era bastante frecuente en los practicantes, debido a la precariedad de los puestos laborales de la profesión.

Su hija María de los Santos cuenta que era un gran amante de la poesía y que llegó incluso a escribir poesías y pequeñas obras de teatro, a la vez que tenían en casa una gran biblioteca (Langa 2009).

Imagen 4. Acta matrimonial de Julio Cabilla

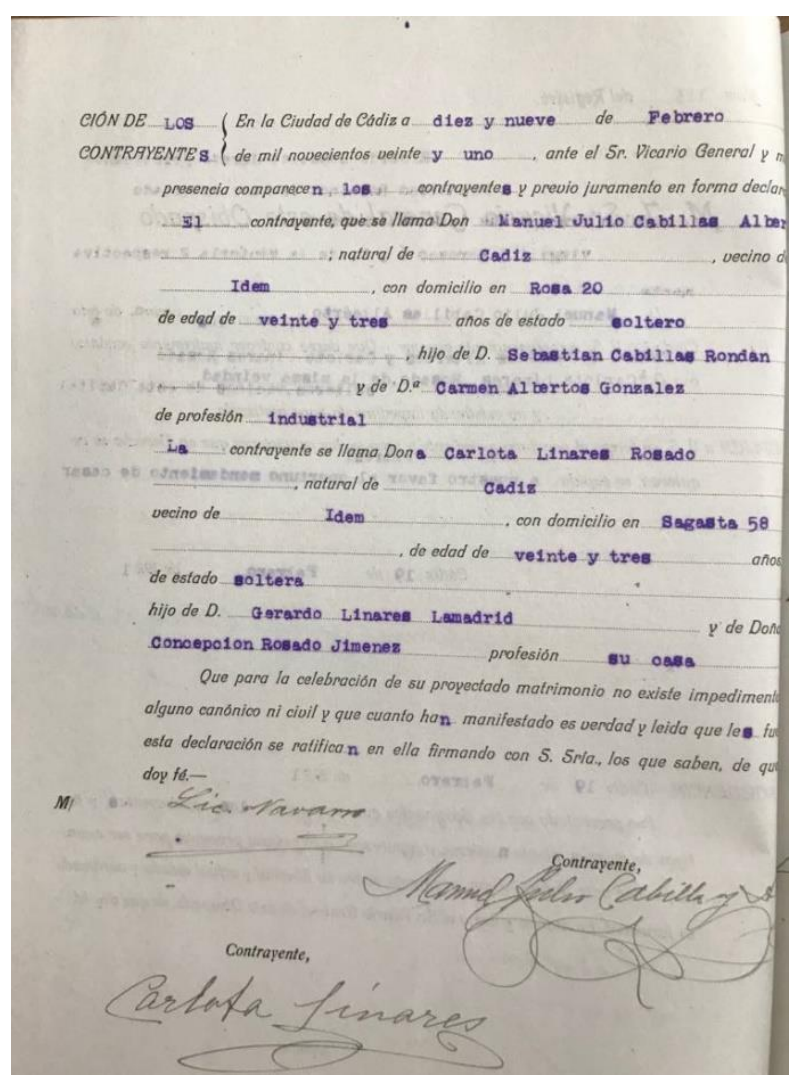

Fuentes: Archivo Histórico Diocesano. Obispado de Cádiz

DOI del artículo:
$\underline{\text { http://dx.doi.org/10.25267/Cuad investig fondos arch UCA.2 }}$
$\underline{019.11 .02}$




\section{ACTIVIDADES SOCIOPOLÍTICAS}

Su acertada escritura le permitió colaborar con el semanario El Pueblo, apareciendo como director, según noticia recogida en el Noticiero Gaditano, del 3 de abril de 1933.

El 23 de marzo de 1935, fue nombrado Secretario del Comité Provincial de Defensa de las Clases Sanitarias, que agrupaba a Médicos, Farmacéuticos, Odontólogos, Veterinarios, Practicantes y Matronas, bajo la presidencia del Ilustre Decano de la Facultad de Medicina de Cádiz, Doctor D. Leonardo Rodrigo Lavín (Diario de Cádiz, 27 de marzo de 1935).

Queda evidenciado el compromiso con la sociedad, además de sus respectivos cargos en el ámbito profesional, también se involucró en actividades de carácter social y político, llegando a ejercer el cargo de Vicepresidente del Comité Provincial del partido socialista y presidente del Sindicato de Practicantes, afectos a la UGT. Tenía una gran amistad con el ilustre doctor y político Rafael Calbo y con el fotógrafo Leonardo Zambonino Cano, ambos fusilados al inicio de la guerra civil española (Langa 2009b).

Los acontecimientos políticos a nivel nacional, se hacían cada vez más insostenibles. Su vida había tenido fechas claves para recordar, pero nunca podría olvidar lo ocurrido el 18 de julio de 1936. El alzamiento militar alteraría totalmente su vida, la de sus seres más queridos y las de todo un país.

Hombre visceral y fiel en sus convicciones, no tuvo reparos en acudir al Gobierno Civil a defender las instituciones republicanas. Su hija relata en las penosas condiciones que volvió a casa tras la lucha infructuosa contra los sublevados. Continúa contando como pudo refugiarse en casa de un amigo, un alto mando de la Falange, que serviría para que salvara la vida. Escondido durante tres años en casa de su madre, en la vecina ciudad de San Fernando, perdía su negocio y su esposa era detenida, situación que le obliga a salir de su escondite y ser inmediatamente detenido.

Fue recluido en la Cárcel Vieja, donde ejercía su profesión y hasta de médico, ante la ausencia de estos.

Un Consejo de Guerra pidió doce años de cárcel, de los que solo cumplió tres, pero fue inhabilitado profesionalmente y tuvo que salir desterrado a 700 kilómetros de su ciudad natal.

Se instaló en Madrid, junto a su esposa y seis hijos, además de su madre. En 1944, cuando gozaba de la libertad provisional, aún tuvo que pasar por la Prisión Provincial de Madrid, acusado de pertenecer a la Masonería. Afortunadamente, por falta de pruebas fue absuelto el 12 de febrero de 1945. A pesar de tanta desgracia junta, supo sacar a su familia hacia adelante, pasando de ser un simple obrero a ocupar un cargo relevante en 
una empresa química. Desgraciadamente, una enfermedad al parecer de origen respiratoria, terminó con su vida a la edad de 57 años (Langa, 2009c).

\section{EPÍlOGO}

En la Revista de Medicina y Cirugía Auxiliar, del Consejo Nacional de Auxiliares Sanitarios (Sección Practicantes), de mayo de 1955, aparece una nota necrológica anunciando su fallecimiento y elogiando la figura de Julio Cabilla, redactado por un compañero y amigo, Alipio García León, residente en Hoyo de Pinares (Ávila). La amistad con Alipio no era casual, era la lógica conjunción de personajes que ejercieron una modesta profesión pero que tenían unas cualidades profesionales y culturales muy destacables. García León, ejerció su profesión durante medio siglo, practicante titular del pueblo. Profesó también de matrón y más de 2500 niños hoyancos, llegaron al mundo de sus manos. Fundó y dirigió el Grupo local de teatro D. Bosco, colaboró con la actividad de la asociación Cultura Joven y fue uno de los fundadores y primer secretario de la Asociación Escuela de Música, que es el vivero de la banda de música de la localidad. Al igual que Julio Cabilla, colaboró publicando escritos en la prensa y revistas culturales y profesionales. El consistorio dio su nombre a una calle de la localidad, entre otros muchos méritos reconocidos.

Julio Cabilla y Alberto tuvo una vida extraordinariamente activa y prolífica, al final de la misma no podía menos que encontrarse con la horma de su zapato en la figura de Alipio, otro practicante y periodista.

Finalizamos el trabajo con la nota dedicada por su buen amigo Alipio.

In Memoriam, ;Julio Cabilla, ha muerto!

¡Ha muerto un gran luchador! Julio Cabilla Alberto, dinámico, inteligente y honrado, gaditano de nacimiento, ha fallecido recientemente en Madrid. Actualmente se hallaba retirado de la profesión; pero merece destacar su larga época de compañero en vanguardia en el Colegio de Cádiz, en el cual desempeñó la Presidencia con entusiasmo y acierto, estimulando a sus compañeros dispersos, logrando la conexión entre todos y despertando en ellos el espíritu de lucha con su vivo ejemplo de actividad incansable, lealtad y pundonor profesional.

Continúa con las alabanzas y comenta como llegó a Hoyo de Pinares, por problemas de salud y de ahí el amplio conocimiento que tenía de Cabilla. Finaliza su semblanza con:

¡Julio Cabilla! Que tu ejemplo de compañero ideal sirva de acicate a tantos compañeros noveles que desconocen tus hermosas virtudes y que tu nombre sea

\footnotetext{
DOI del artículo:

http://dx.doi.org/10.25267/Cuad investig fondos arch UCA.2 $\underline{019 . i 1.02}$
} 
para ellos, antorcha que ilumine sus pasos incipientes en el seno de nuestra amada profesión.

\section{FUENTES DOCUMENTALES}

- Archivo de la Universidad de Cádiz. Expediente personal de Julio Cabilla Alberto. Legajo 165 (3)-74 FM

- Archivo Histórico Diocesano. Obispado de Cádiz. Certificado de matrimonio de Julio Cabilla y Alberto.

\section{REFERENCIAS BIBLIOGRÁFICAS}

- Alberto Cabilla, Julio. El intrusismo avanza. El Practicante Gaditano: Revista mensual, Profesional y Científica. Cádiz. Colegio de Practicantes 1916. Año I, nº1. (p. 6-7)

- Alberto Cabilla, Julio. Mi saludo. El Practicante Gaditano: Revista mensual, Profesional y Científica. Cádiz. Colegio de Practicantes 1920. Año V, n³9. (p.1)

- Colegio Oficial de Enfermería de Ávila. Homenaje a D. Alipio García León en el Hoyo de Pinares. 16 de mayo del 2008 [en línea]. Disponible en: http://www.enfermeriaavila.com/modules.php?name=News\&file=article \&sid=4036

- GARCía León, Alipio, 1955. In Memoriam, ¡Julio Cabilla, ha muerto! [en línea]. En: Revista de Medicina y Cirugía Auxiliar, del Consejo Nacional de Auxiliares Sanitarios (Sección Practicantes) Madrid, mayo 1955, p.18. Disponible en: https://www.codem.es/boletines-y-revistas-2/medicina-y-cirugia-auxiliar-organooficial-del-consejo-general-de-colegios-oficiales-de-practicantes-189

- LANGa Nuño, Concha, 2009. Periodismo y Represión: Los periodistas gaditanos y el franquismo (1936-1945). Cádiz, Quorum Editores, p. 259-263.

- El Noticiero Gaditano. En el Hotel Atlántico. Hemeroteca Biblioteca Municipal Celestino Mutis. Cádiz. Año XV. 3 de abril de 1933. No 7082, p.1.

- Padilla Mesa, Antonio. Recopilación de la Hemeroteca del Diario de Cádiz. Archivo del Excmo. Colegio de Enfermería de Cádiz. 